\title{
Supply chain technology adoption: Its clarification, evolution, classification, and practicality in textile and apparel industry
}

\author{
Khai-Loon Lee*, Zulkifli Mohamed Udin, Mohamad Ghozali Hassan \\ School of Technology Management and Logistics, College of Business, Universiti Utara Malaysia, 06010 Sintok, Kedah Darul Aman, \\ Malaysia
}

\section{Email address:}

kyle.kllee@gmail.com (K. L. Lee), zulkifli@uum.edu.my (Z. M. Udin), ghozali@uum.edu.my (M. G. Hassan)

\section{To cite this article:}

Khai-Loon Lee, Zulkifli Mohamed Udin, Mohamad Ghozali Hassan. Supply Chain Technology Adoption: Its Clarification, Evolution, Classification, and Practicality in Textile and Apparel Industry. International Journal of Business and Economics Research. Special Issue: Supply Chain Management: Its Theory and Applications. Vol. 3, No. 6-1, 2014, pp. 15-21. doi: 10.11648/j.ijber.s.2014030601.13

\begin{abstract}
In today's dynamic business environment, technology is the most powerful tools to sustain in the competitive global market place. However, supply chain technology is the 21 st century global supply chain management tool for achieving supply chain operational competitiveness. The global manufacturing sector, especially the textile and apparel industry are essentially known for its supply chain dependency. Companies are struggling to find ways to improve their reliability, responsiveness, agility, and costs and in turn competitiveness by changing their operations through adopting new supply chain technology. Even though information technology is widely implemented and studied in countless different contexts, but the clarifications between information technology and supply chain technology are still unclear. In this study, the diversity between information technology and supply chain technology is interpreted through a thorough and comprehensive review of the literatures. From there, the evolution of supply chain technology is undoubtedly tracked and the classification of supply chain technology has been clearly stated. The practical contributions of supply chain technology adoption to supply chain performance are the most excited part of this study. The result of this study could be used as a precursor to support future researchers in further investigation on this area. Thus, recommendations and suggestions for future study directions are indicated.
\end{abstract}

Keywords: Clarification, Evolution, Classification, Practicality, Technology, Information Technology, Supply Chain Technology, Textile and Apparel Industry

\section{Introduction}

In the 21 st century, almost all companies are in the race for improving its competitiveness in the global market. The nature of today's market, operation is electronically connected to effectively and efficiently manage the supply chain. This is one of the most popular methods that companies used to improve their level of supply chain management with the objective of being reliable, agile, responsive, and costs optimization in competing in the dynamic market competition. In an exertion to achieve this, numerous companies have adopted supply chain technology in aiding their supply chain operation activities. Based on Council of Supply Chain Management Professionals [1], "supply chain management encompassing the planning and management of all activities involved in sourcing and procurement, conversion, and all logistics management activities which include coordination and collaboration with channel partners such as suppliers, intermediaries, third-party service providers, and customers. In essence, supply chain management integrates supply and demand management within and across companies." All this highlight the importance of supply chain technology in integrating the internal and external supply chain [2], [3]. Although, supply chain technology is a popular tools to manage companies' operation activities, but there is no common definition for supply chain technology [4]. However, based on the previous study, several researchers have defined their understanding toward supply chain technology in their study [4]-[6] and further discussed the competitiveness of supply chain technology.

The following sections further discussed the issues of this study; the clarification between information technology and supply chain technology; the evolution of supply chain 
technology; the classification of supply chain technology; the practical contribution to the practitioner; the results and discussions, conclusion and implications, and recommendations as well are presented at the end of the study.

\section{Issues of the Study}

Textile and apparel industry is fragmented with small and medium-sized enterprises that support both upstream and downstream of the supply chain [7]. Based on the directory of Federal of Malaysian Manufacturer [8], Malaysian Textile and apparel industry is made up of $25 \%$ large enterprises, $44 \%$ medium enterprises, $30 \%$ small enterprises, and 1\% micro enterprises. Naturally, small and medium-sized enterprises were not aware on the support of technology, especially, supply chain technology due to costly for them to adopt, since they have resource limitation [7], [9]-[11]. However, the nature of today's market revealed that all business operations should be electronically connected. This is the most effective way to enable the effective and efficient business activities being conducted continuously.

Based on the aforementioned, basically, supply chain technology adoption able to solve most of the issues in the supply chain [12], [13]. Based on the literature, in the industry, there is an adoption of supply chain technology in operating their business [5]. However, there are relatively handful research materials available on supply chain technology, especially in Malaysian textile and apparel industry. This leads to the number of queries on supply chain technology. What are the differences between information technology and supply chain technology? When supply chain technology starts to emerge in textile and apparel industry? What are the categories of supply chain technology? Does supply chain technology practically contribute to textile and apparel industry? What are the benefits that gain from the adoption of supply chain technology?

\section{Clarification}

\subsection{Technology}

Originally, the term "technology" is known as "useful arts" since the last 200 years [14]. In 1937, the American sociologist defines technology as all machines, tools, instruments, utensils, weapons, clothing, housing, communicating and transporting devices and the skills by which we create and use them [15]. Through the day to day innovation and revolution, scholars and dictionaries have offered a range of definitions. Dictionary.com (2014) defined technology as "the branch of knowledge that deals with the creation and use of technical means and their interrelation with life, society, and the environment, drawing upon such subjects, industrial arts, engineering, applied science, and pure science." However, some authors suggested that technology can be generally defined as "the entities, both material and immaterial, created by the application of mental and physical effort in order to achieve some value" [17]. From the above definitions, in simple words, technology can be defined as a collection of techniques, which include tools, machines and equipment that may be used to solve and explain real-world problems.

Technology is a challenge of traditional norms. In the present day, technologies significantly affect human, society, the global economy as well as other animal species' ability to control and adapt to their natural environments. The term "technology" can be applied broadly or to specifically such as construction technology, medical technology, and information technology. Basically, most technology enables process simplification, standardization, automation, and hence improving communications, process efficiency, organizational productivity, and effectiveness. However, not all created technology been used for peaceful purposes. For instance, the development of weapons can be a tool to provide safety for human, but at the same time increasing destructive power to the world.

\subsection{Information Technology (IT)}

The global business competition has revealed the needs of information technology in securing business competitiveness. Nowadays, the word " $I T$ " or "information technology" is frequently applied by most of the companies and even individual in the world. Therefore, the information technology is playing an important role at the moment and future as well. Information technology consists of wide range of technologies, including multimedia, telecommunications, computer hardware and software that involved in information handling and processing [18]. The main functions of information technology is to store, retrieve, manipulate, and send information and transmit information, especially the development, installation, implementation, and management of the information for conducting business through the integration of telecommunications equipment and computers application [19]-[21].

In addition, information technology encompasses information system (IS) and information and communication technology (ICT). Information systems are the study of hardware and software that usually people and organizations applied to gather, filter, process, create, monitor, control, and distribute data [22], [23]. The final contribution is to support management and operation teams to make the informed decisions [24]. Similarly, information and communication technology is frequently used as a stretched synonym for information technology, but it is more focused upon the function of communications and the integration of telecommunications by electronic equipment [25]. The further discussions of information system and information and communication technology are as follows.

\subsubsection{Information System (IS)}

Generally, information systems have been defined to represent any of an extensive combination of computer software, computer hardware, communication technology designed to handle information related to commercial processes [26]. In more detail, information systems are the 
study of hardware and software that usually people and organizations applied to gather, filter, process, create, monitor, control, and distribute data [22], [23]. McLaren [27] further defined that the information system is an "enterprise or internal organizational systems used to coordinate information between the manufacturers, suppliers, distributors, and other partners in the supply chain" to minimize costs and improve the responsiveness of the supply chain. However, Tarokh and Saroor [28] noted that information system provided relevant, timely and high quality information flow to effectively supports decision making and for synchronizing material flows at all levels within the supply chain. Thus, in overall, this is to assist the management and operation teams to make the informed decisions with information technology [24], [29]. Sabherwal and Chan [30] and Qrunfleh and Tarafdar [31] noted that information system is used for efficiency and flexibility.

In information systems, the efficiency is referring to the use of operational support systems or intra-organizational and inter-organizational systems such as EDI, ERP, e-procurement systems for a supply chain process. Basically, the purposes of information systems are used to monitor, control, and facilitate day to day operations in the supply chain. However, the term flexibility in information system is referring to the use of the market information systems such as production scheduling, demand forecasting, market analysis and CRM applications for market quick strategic decisions. The information systems are mostly used to monitor product and market trends and quick respond to fluctuations by propose a plan for delivery lead times and production schedules.

\subsubsection{Information and Communication Technology (ICT)}

Information and communication technology has become indispensable as a factor which creates a competitive advantage for business [32]. It is frequently used as a stretched synonym for information technology, but it is more focused upon the function of communications and the integration of telecommunications by electronic equipment [25]. Based on the study of Bhatnagar and Schware [33], Information and communication technology applications can be generally categorized into three, which are decision support to public administrators (i.e. geographical information system), improving service to citizens, and empowering citizens to access information and knowledge. It could make such knowledge and information visible to large communities. However, the administrators must be willing to change their working style to use the information and communication technology to achieve higher performance.

\subsubsection{Supply Chain Technology (SCT)}

Although, supply chain technology is universally accepted, but there is no common definition of supply chain technology [4]. Therefore, several researchers have defined their understanding toward supply chain technology in their study. Singh [5] defined supply chain technology as an application to transform original data into information and knowledge that can efficient and effective the business activities. While, Blankley [6] defined supply chain technology as an information technology that specifically used to manage or support elements or components of the supply chain. Comprehensively, Kamaruddin and Udin (2009) defined supply chain technology as "a technology or a system that used to coordinate and integrating information flow electronically throughout the internal and external supply chain to generate effectiveness and efficiency of business processes."

In the current decade, supply chain technology is constantly changing and improving the way of doing business and solving problems [13]. Thus, it plays a vital role in managing the supply chain in which intelligently provides connection between people, processes, data, and things. All companies are aiming to higher benefits such as offering new methods to create value by greater and more efficiently organizing the use of physical, financial, information, and human resources. In this context, supply chain technology is one of the most popular adoptions that lead companies to the direction of success. As highlighted in Global Information Technology Report [34], this study believes that supply chain technology would demonstrate a positive impact on short and long term performance, and this study further believes the next wave of new supply chain technology adoption will further advance the growth of the textile and apparel supply chain management.

Based on the aforementioned discussions, Figure 1 is developed to simplify the understanding on supply chain technology. It is conceptualizing the relationship between information technology and supply chain technology.

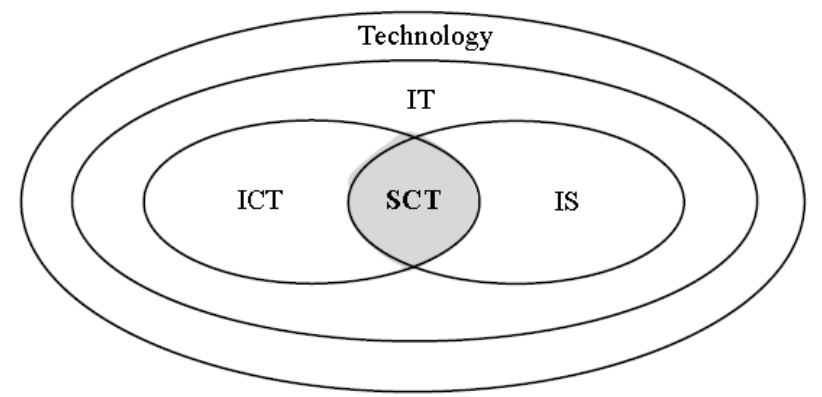

Figure 1. Conceptualizing the relationship between IT and SCT.

\section{Evolution}

\subsection{Evolution of Supply Chain Technology}

The concept of supply chain management is originally derived from the logistical concept since 1950 and matured in 1970 [35]-[38]. On the moment, technology is purely used for information processing. The logistical concept is slowly evolving into the supply chain management concept and initiated the supply chain management concept with the supply chain technology since 1980. The introduction of supply chain technology leads to increasing the innovation of operation within the industry. Besides, the useful of supply chain technology lead to the increasing introduction of variety supply chain technology in the market. Nowadays, the supply chain technologies are becoming an essential management 
tool for companies in the supply chain to lock their competitiveness. Figure 2 illustrated the evolution of supply chain technology and some of the examples of supply chain technology.

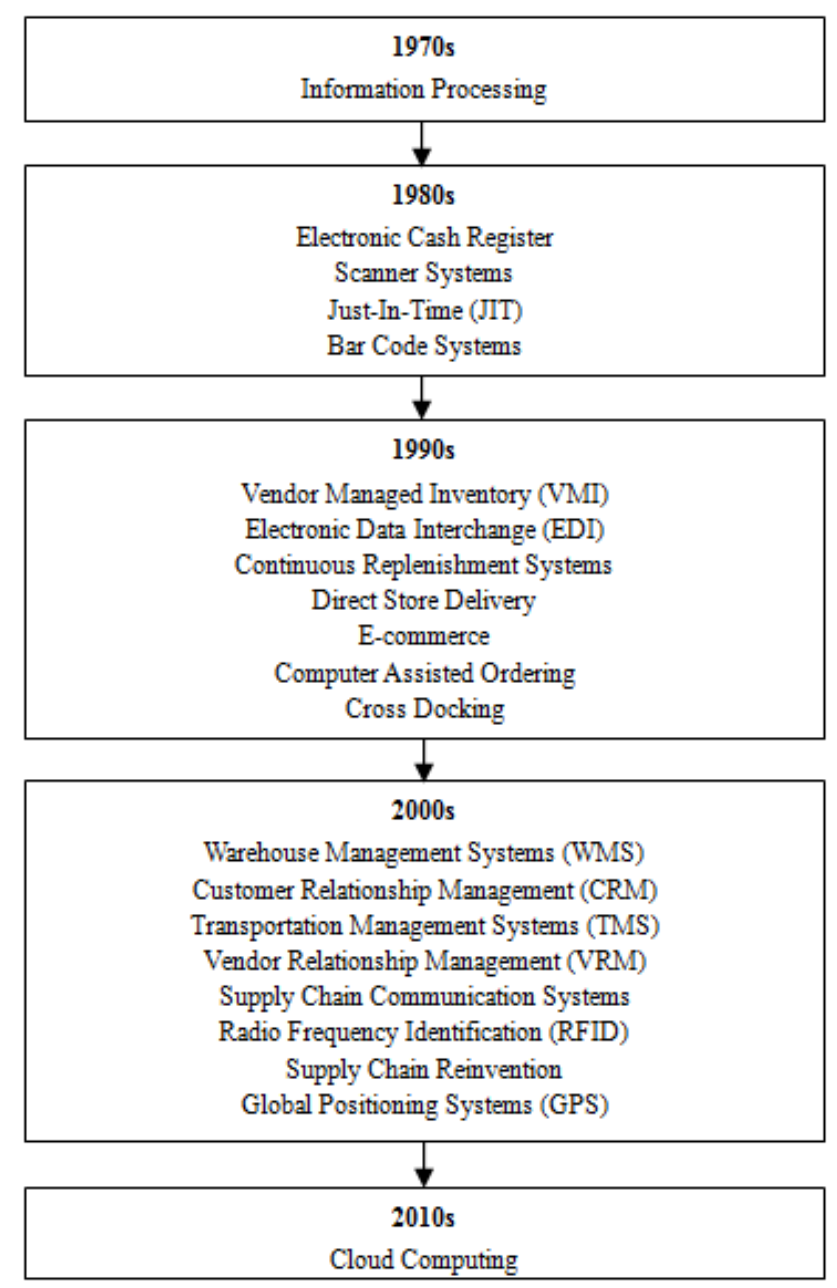

Source. Adapted from [39], [40]

Figure 2. Evolution of supply chain technology adoption.

The concept of supply chain management started to emerge in the mid-1960s, and the first publication took place in 1982. Figure 2 illustrated the evolution of the supply chain technology from 1970s to 2010s. Based on the evolution, initially, the supply chain technology is only applied for a single function which is information processing. However, there are increasing numbers of supply chain technology been introduced since 1980s, which include scanner systems, bar code systems, electronic cash register, and just-in-time (JIT). It has attracted attention of researchers since 1990 [41], [42] and gained an incredible attention from both academics and practitioner's community since 2000 [43]. Similarly, supply chain technology has attracted attention of researchers and practitioners since supply chain technology can make major reduction in costs [44]. Thus, the number of supply chain technology has increased dramatically. Vendor managed inventory (VMI), Electronic data interchange (EDI), continuous replenishment systems, computer assisted ordering, e-commerce, cross docking, and direct store delivery in 1990s, while supply chain reinvention, transportation management systems (TMS), warehouse management systems (WMS), customer relationship management (CRM), supply chain communication systems, radio frequency identification (RFID), vendor relationship management (VRM), and global positioning systems (GPS) in 2000s.

Nowadays, supply chain technology such as cloud computing has to become a common management tool in assisting firms expand their competitiveness in the global and multinational market [40]. Therefore, supply chain technology had proven to be vitally important for textile and apparel industry [9].

\section{Classification}

\subsection{Classification of Supply Chain Technology}

Table 1. Category of supply chain technology

\begin{tabular}{l}
\hline Software \\
Computer-Aided Design Systems (CAD) \\
Transportation Management Systems (TMS) \\
Demand Forecasting Management Systems (DFM) \\
Enterprise Resource Planning Systems (ERP) \\
Customer Relationship Management Systems (CRM) \\
Warehouse Management Systems (WMS) \\
Cloud Technology \\
E-Business \\
E-Commerce Technologies \\
Electronic Funds Transfer (EFT) \\
Internet \\
Electronic Mail (email) \\
Electronic Data Interchange (EDI) \\
Wireless and Mobile Devices \\
Visibility and Productivity \\
Bar-Coding Technology \\
Radio Frequency Identification Systems (RFID) \\
Global Positioning Systems (GPS) \\
Geo-Coded Tracking Systems (GCTS) \\
Satellite Tracking Systems \\
Process Advances \\
Vendor Managed Inventory (VMI) \\
Lean Manufacturing \\
Six Sigma \\
Carbon Footprint Management \\
Vendor Managed Replenishment (VMR) \\
\hline
\end{tabular}

Source. Adapted from Forger (1998); Gunasekaran et al. (2001); Li (2002); Dawson (2002); Patterson et al. (2003); Helo and Szekely (2005); Bharati and Chaudhury (2006); Fawcett et al. (2007); Xuhua (2008); Jeffers et al. (2008); Lin (2008); Kamaruddin and Udin (2009); Vijayasarathy (2010); Slone et al. (2010); Tseng et al. (2011), Glenn Richey, Tokman, and Dalela (2009), Karmakar and Tewari (2014), Chuu (2014), and Peppa and Moschuris (2013)

In this section, the literature available on supply chain technology in supply chain management has been reviewed thoroughly for its application and development. Based on the applications and developments, the supply chain technologies have been classified under four categories, which is software, visibility and productivity, e-business, and process advance 
technology [44]. With an effort to be current in the research field, Table 1 illustrated the classification of supply chain technology and some of the examples. These are not the full versions of supply chain technology in the existing industry. However, those supply chain technologies presented in Table 1 are the most popular supply chain technology that adopted in the industry.

The sophisticated supply chain technologies enable many of the most promising supply chain opportunities. A wide range of supply chain technology exists, and the benefits can be huge. However, serious risks lurk nearby or damage a firm's supply chain. Thus, the study of Slone et al. [44] suggested supply chain executive and supply chain top management to have high level understanding and knowledge of supply chain technologies to achieve a distinct competitive advantage. They are playing a critical role in ensuring that supply chain contributes rather than hampers a strategy for supply chain excellence. However, the supply chain processes and systems are complex and no single person understands everything. In practical case, sometime technical people become irrelevant due to their own arrogance. This issue has been faced by production planners in an apparel company during a supply chain audit. Now, the challenge of the supply chain technology is to simplify the complex technology and further improve the performance of the systems.

\section{Conclusion and Implications}

This study has been demonstrated that information technology or more specifically supply chain technology has become an essential element for business survival and sustained competitiveness in the global market. Supply chain technology is a critical, enabling step toward building a strategy for supply chain excellence. At the moment, although the literature on supply chain technology is not exhaustive, but it serves as a comprehensive base for an understanding of supply chain technology in supply chain management. The diversity of information technology and supply chain technology is not clearly stated in the existing literatures. As a result of this study, the clarification, evolution, and classification of supply chain technology had been stated clearly. This is a primary study on supply chain technology precisely. Thus, it provides a valuable knowledge for academicians and practitioners to enhance their understanding on supply chain technology. It would be the foundation to support future researchers in further exploring in this context. Despite the facts that supply chain technologies are becoming increasingly universal, the queries of adoption, usage, and usefulness are remains essential, especially for developing countries. As a suggestion for future research, the empirical study may be conducted to enhance the understanding about the relationship of supply chain technology on supply chain performance.

\section{Acknowledgements}

The authors would like to extend the appreciation to
Universiti Utara Malaysia (UUM) who has provided the academic development opportunity and postgraduate academic support. Besides, our gratitude also goes to Ministry of Education Malaysia, who has provided the generous financial support through the Fundamental Research Grant Scheme (FRGS).

\section{References}

[1] Council of Supply Chain Management Professionals, "CSCMP Supply Chain Management," Council of Supply Chain Management Professionals, 2013. [Online]. Available: http://cscmp.org/about-us/supply-chain-management-definitio ns. [Accessed: 14-Jun-2013].

[2] D. Bratić, "Achieving a competitive advantage by SCM," IBIMA Bus. Rev. J., vol. 2011, pp. 1-13, Jun. 2011.

[3] K. C. Tan, V. R. Kannan, and R. B. Hanfield, "Supply chain management: Supplier performance," Int. J. Purch. Mater. Manag., vol. 34, no. 2, pp. 2-9, 1998.

[4] N. K. Kamaruddin and Z. M. Udin, "Supply chain technology adoption in Malaysian automotive suppliers," J. Manuf. Technol. Manag., vol. 20, no. 3, pp. 385-403, 2009.

[5] N. Singh, "Emerging technologies to support supply chain management," Commun. ACM, vol. 46, no. 9, pp. 243-247, 2003.

[6] A. Blankley, "A conceptual model for evaluating the financial impact of supply chain management technology investments," Int. J. Logist. Manag., vol. 19, no. 2, pp. 155-182, 2008.

[7] B. Ma and K. J. Zhang, "Research of apparel supply chain management service platform," in Management and Service Science, 2009. MASS'09. International Conference, 2009, pp. $1-4$.

[8] FMM Directory, "Federation of Malaysia Manufacturers Directory," Malaysia, 2013.

[9] J. K. C. Lam and R. Postle, "Textile and apparel supply chain management in Hong Kong," Int. J. Cloth. Sci. Technol., vol. 18, no. 4, pp. 265-277, 2006.

[10] F. L. Leng and S. Zailani, "Effects of information, material and financial flows on supply chain performance: A study of manufacturing companies in Malaysia," Int. J. Manag., vol. 29, no. 1, pp. 293-314, 2012.

[11] S. Karmakar and M. Tewari, "Using IPRs to protect niches? Evidence from the Indian textile and apparel industry," 270, 2014.

[12] M. Chen, D. Zhang, and L. Zhou, "Empowering collaborative commerce with Web services enabled business process management systems," Decis. Support Syst., vol. 43, no. 2, pp. 530-546, Mar. 2007.

[13] W. D. Cooper, "A fresh look at the U.S./chinese textile and apparel supply chain question," J. Text. Apparel, Technol. Manag., vol. 8, no. 2, pp. 1-16, 2013.

[14] G. Crabb, Universal Technological Dictionary, or Familiar Explanation of The Terms Used in All Arts and Sciences. London: Baldwin, 1823. 
[15] R. Bain, "Technology and state government," Am. Sociol. Rev., vol. 2, no. 6, pp. 860-874, 1937.

[16] Dictionary.com, "Definition of technology," 2014.

[17] National Science Foundation, "Industry, technology and the global marketplace: International patenting trends in two new technology areas," Science and Engineering Indicators, 2002. .

[18] S. L. Huff and M. C. Munro, "Information technology assessment and adoption: A field study," in MIS Quarterly, 1985, no. December, pp. 327-341.

[19] The Free Dictionary, "Definition of information technology," Free Online Dictionary, Thesaurus and Encyclopedia, 2013. [Online]. www.thefreedictionary.com/information+technology. [Accessed: 04-Sep-2013].

[20] Science Dictionary, "Definition of information technology," The American Heritage, Houghton Mifflin, 2013. .

[21] Oxford Dictionaries, "Definition of information technology," Oxford University Press, 2013.

[22] J. A. Archibald, "Computer science education for majors of other disciplines," in Proceedings of the May 19-22, 1975, National Computer Conference and Exposition, 1975, pp. 903-906.

[23] P. J. Denning, "Computer science: The discipline," Encyclopedia of Computer Science, no. July 1999. A. Ralston and D. Hemmendinger, Eds, pp. 1-27, 1999.

[24] G. P. Huber, "A theory of effects of the information technologies advanced on organizational design, decision making intelligence, and decision making," Acad. Manag. Rev., vol. 15 , no. 1 , pp. 47-71, 1990.

[25] Cambridge Dictionaries Online, "Definition of information and communication technology," Cambridge University Press, 2013. .

[26] S. Flowers, Software failure: Management failure. Chichester, UK: John Wiley, 1996.

[27] T. S. McLaren, M. M. Y. Head, and Y. Yuan, "Using competitive strategy patterns to determine ideal supply chain management information systems capabilities," Int. J. Internet Enterp. Manag., vol. 2, no. 1, pp. 45-61, 2004.

[28] M. J. Tarokh and J. Soroor, "Supply chain management information systems critical failure factors," in Service Operations and Logistics, and Informatics, 2006. SOLI'06. IEEE International Conference, 2006, pp. 425-431.

[29] M. J. Earl, Management Strategies for Information Technology. New York, NY: Prentice-Hall, Inc., 1989.

[30] R. Sabherwal and Y. E. Chan, "Alignment between business and IS strategies: A study of prospectors, analyzers, and defenders,” Inf. Syst. Res., vol. 12, no. 1, pp. 11-33, 2001.

[31] S. Qrunfleh and M. Tarafdar, "Supply chain information systems strategy: Impacts on supply chain performance and firm performance,” Int. J. Prod. Econ., pp. 1-11, 2013.

[32] M. S. Castro, K. Ramos, and L. Molinaro, "Information and communication technology's professionals profile: Executives' perception analysis," in European Conference on Information Management \& Evaluation, 2009, pp. 24-34.
[33] S. Bhatnagar and R. Schware, "Information and communication technology in rural development: Case studies from India," India, 2000.

[34] The Global Information Technology Report: Growth and Jobs in a Hyperconnected World, "World Economic Forum," 2013.

[35] M. M. Habib and C. Jungthirapanich, "An integrated framework for research and education supply chain for the universities," in 2008 4th IEEE International Conference on Management of Innovation and Technology, 2008, pp. $1027-1032$.

[36] K. L. Lee, Z. M. Udin, and M. G. Hassan, "Global supply chain capabilities in Malaysian textile and apparel industry," Int. J. Supply Chain Manag., vol. 3, no. 2, pp. 31-40, 2014.

[37] K. L. Lee, Z. M. Udin, and M. G. Hassan, "Supply chain capabilities: A study in textile and apparel industry," in Proceedings of 1st International Conference on Innovation Driven Supply Chain, 2014.

[38] M. Habib, "An empirical research of ITESCM (integrated tertiary educational supply chain management) model," in Management and Services, M. Habib, Ed. Bangladesh: Sciyo, 2010, pp. 1-24.

[39] J. D. Collins, W. J. Worthington, P. M. Reyes, and M. Romero, "Knowledge management, supply chain technologies, and firm performance," Manag. Res. Rev., vol. 33, no. 10, pp. 947-960, 2010 .

[40] C. G. Cegielski, L. J.-F. Allison, Y. Wu, and B. T. Hazen, "Adoption of cloud computing technologies in supply chains: An organizational information processing theory approach," Int. J. Logist. Manag., vol. 23, no. 2, pp. 184-211, 2012.

[41] W. D. Cooper, "Textile and apparel supply chain management technology adoption,” J. Text. Apparel, Technol. Manag., vol. 5, no. 2, pp. 1-22, 2006.

[42] S. H. Huan, S. K. Sheoran, and G. Wang, "A review and analysis of supply chain operations reference (SCOR) model," Supply Chain Manag. An Int. J., vol. 9, no. 1, pp. 23-29, 2004.

[43] F. T. S. Chan and H. J. Qi, "An innovative performance measurement method for supply chain management," Supply Chain Manag. An Int. J., vol. 8, no. 3, pp. 209-223, 2003.

[44] R. E. Slone, J. P. Dittmann, and J. T. Mentzer, "The new supply chain agenda: The five steps that drive real value," Harvard Bus. Sch. Press, 2010.

[45] G. Forger, "The brave new world of supply chain software, modern material handling," 1998. [Online]. Available: www.manufacturing.net/scl/yearbook/trends.htm. [Accessed: 05-Mar-2013].

[46] A. Gunasekaran, C. Patel, and E. Tirtiroglu, "Performance measures and metrics in a supply chain environment," Int. J. Oper. Prod. Manag., vol. 21, no. 1/2, pp. 71-87, 2001.

[47] S. H. Li, "Developing mesures of supply chain management performance," in Proceedings of the Annual Meeting of the Decision Science Institute, 2002.

[48] A. Dawson, "Supply chain technology," Work Study, vol. 51, no. 4, pp. 191-196, 2002.

[49] K. A. Patterson, C. M. Grimm, and T. M. Corsi, "Adopting new technologies for supply chain management," Transp. Res. Part E Logist. Transp. Rev., vol. 39, no. 2, pp. 95-121, Mar. 2003. 
[50] P. Helo and B. Szekely, "Logistics information systems: An analysis of software solutions for supply chain co-ordination," Ind. Manag. Data Syst., vol. 105, no. 1, pp. 5-18, 2005.

[51] P. Bharati and A. Chaudhury, "Studying the current status of technology adoption," Commun. ACM, vol. 49, no. 10, pp. 88-93, 2006.

[52] S. E. Fawcett, P. Osterhaus, G. M. Magnan, J. C. Brau, and M. W. McCarter, "Information sharing and supply chain performance: The role of connectivity and willingness," Supply Chain Manag. An Int. J., vol. 12, no. 5, pp. 358-368, 2007.

[53] P. Xuhua, "Information technology in logistics and supply chain management," in Proceedings of the IEEE International Conference on Automation and Logistics, 2008, no. 2006, pp. $2185-2188$

[54] P. I. Jeffers, W. A. Muhanna, and B. R. Nault, "Information technology and process performance: An empirical investigation of the interaction between IT and non-IT resources,” Decis. Sci., vol. 39, no. 4, pp. 703-735, Nov. 2008.

[55] C. Y. Lin, "Determinants of the adoption of technological innovations by logistics service providers in China," Int. J. Technol. Manag. Sustain. Dev., vol. 7, no. 1, pp. 19-38, 2008.
[56] L. R. Vijayasarathy, "An investigation of moderators of the link between technology use in the supply chain and supply chain performance," Inf. Manag., vol. 47, no. 7-8, pp. 364-371, Dec. 2010.

[57] M. L. Tseng, K. J. Wu, and T. T. Nguyen, "Information technology in supply chain management: a case study," Procedia - Soc. Behav. Sci., vol. 25, pp. 257-272, Jan. 2011.

[58] R. G. Richey, M. Tokman, and V. Dalela, "Examining collaborative supply chain service technologies: A study of intensity, relationships, and resources," J. Acad. Mark. Sci., vol. 38, no. 1, pp. 71-89, Mar. 2009.

[59] S. J. Chuu, "An investment evaluation of supply chain RFID technologies: A group decision-making model with multiple information sources," Knowledge-Based Syst., vol. 66, pp. 210-220, Aug. 2014.

[60] V. P. Peppa and S. J. Moschuris, "RFID technology in supply chain management: A review of the literature and prospective adoption to the Greek market," Glob. J. Eng. Educ., vol. 15, no. 1, pp. 61-68, 2013. 